\title{
MULTIFAMILY/MULTIDIAGNOSTIC PSYCHOEDUCATIONAL SESSIONS IN A PSYCHIATRIC DAY HOSPITAL SETTING
}

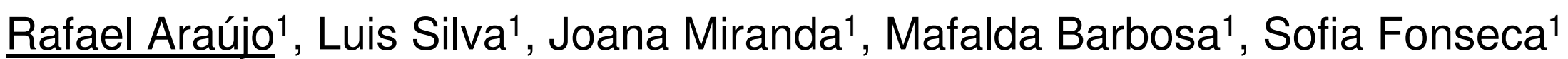 \\ ${ }^{1}$ Centro Hospitalar de Leiria, Serviço de Psiquiatria e Saúde Mental, Leiria, Portugal
}

The evolution of treatments used in Psychiatry has been keeping the individuals who have mental disorders in the community, prioritizing outpatient treatment and avoiding prolonged hospital stays and institutionalization. Thus, responsibility regarding care provided to the patient is increasingly on the families, which are an important mediator between the patient and the healthcare system.

Mental disorders, as entities that impair the domains of thought and behavior, assume significant proportions not only in the life trajectory of the patients but also their families. Frequently however, family members feel unprepared and carry many doubts regarding the care of a mentally ill relative.

Psychoeducation has assumed a progressively more important role in helping these families, introducing them to mental illness and teaching how to deal with most of the frequently encountered challenges.

Several studies have proven the efficacy of different psychoeducational approaches both for patient and families but scarce information exists on multifamily/multidiagnostic programmes, which expectantly present a better cost-benefit ratio, a richer learning process and reduction of stigma through experience-sharing between members, as well as a broader support network.

\section{OBJECTIVES}

- Understand the system of beliefs of the family members and help them create a structured and predictable environment at home that provides the necessary support as well as an adequate degree of expectations and demands concerning the ill person

- Support the families in the process of adaptation to their relative's mental disorder, not only by educating on mental health care but also promoting the satisfaction of family member's basic human needs and maximum independence in daily living

- Implicate the families in a therapeutic alliance with health care professionals, actively supporting the patient throughout the treatment and improving his compliance to therapeutic recommendations.

- Provide a space where members can express and share fears, doubts and necessities by incentivating debate between members throughout the session period in order to create a support network and broaden their perception on the main problems and doubts that families face

- Understand and evaluate the impact Multifamily/Multidiagnostic structured sessions of psychoeducation can have in the management of the mentally ill, both for patients and their families $\rightarrow$ Questionnaires

DESIGN The Psychoeducational program is aimed at the Families/Caregivers (FC's) of patients $(\approx 16)$ attendig the Psychiatric Day Hospital of Centro Hospitalar de Leiria. Maximum 2 FC's per patient per session.

Team:

- 1 Psychiatrist (permanent)

- 1 Nurse (permanent)

- 1 Psychologist (variable)

- 1 Social Worker (variable)

- 1 Occupational Therapist (variable)

\section{1 - Presentation of the Sessions/Group}

Team \& FC's

Objectives

Working method

Planification

Filling in Questionnaires

\section{2 - Free Session}

Free discussion on the thematics brought in by the FC's

Understanding the beliefs of the FC's

Sharing experiences between FC's \& team

\section{3 - Psychiatric Disorders}

Diagnostic Classification

Main characteristics

Types of medical care

Treatment

Prevention

Discussion of the theme presented

4 - Presentation of the Day Hospital

General organization

Working method \& schedule

Objectives

Rehabilitation activities

Discussion of the theme presented

\section{5 - Communication}

Components \& types of communication

How to communicate

How to listen

Discussion of the theme presented

Session held together with the patients

Shared snack - FC's, patients \& team

At the end of each session there is a round of free questions by each of the FC's on any topic related to mental health care $\rightarrow$ questions directly related to a family member are reserved to an interview with the Psychiatrist responsible for the patient.

\section{Questionnaires}

In order to evaluate the impact and efficacy of the psychoeducative program we opted for the Family Problems Questionnaire since it is validated for Portuguese language and provides a reliable measurement of both the subjective and objective impact that severe mental disorders have in the patients and their families. It is also tailored to evaluate the efficacy of psychoeducative interventions with families throughout time.

We will also apply a questionnaire created by the team in order to assess the FC's general satisfaction, perception of change in themselves/family system and their ill relative, as well as suggestions for the future. Another questionnaire created by the team will be filled in by the patients at the beginning and the end of the programme, to evaluate their perception of the impact of the programme both in their FC's and themselves.

McFarlane WR et. al.,,J Marital Fam Ther. 2003 Apr;29(2):223-45 § Bernheim KF et. al., Hosp Community Psychiatry. 1988 Jan;39(1):63-8 § Xavier M et. al. PSICOLOGIA, SAÚDE \& DOENÇAS, 2002, 3 (2), 165-177 \ Eisner LR et. al., Behav Ther. 2008 Dec;39(4):375-85 \ Breitborde NJ et. Al. BMC Psychiatry. 2011 Jan 12;11:9 ๆ Boylan K et. al., J Am Acad Child Adolesc Psychiatry. 2013 Jul;52(7):699-708 ף Katzuki F et. al., BMC Psychiatry. 2018 Jun 22:18(1):207 I Teixeira S et. al., Psychiatr Rehabil J. 2015 Sep;38(3):263-7 